Postoperative thromboembolic disease and oral contraceptives

N Puttick, FFARCs, and Melanie Jones, FFARCS

Pyomyositis associated with hepatitis Lindsay Dow, MRCP, and others.

Delivery after caesarean section

P Maouris, MB, and P Macrow, MB; R P

Gleeson, MRCOG, and others

Randomised comparison of early versus late induction of labour in post-term pregnancy

PT Mohide, FRCsC; P Bergsj $\varnothing$, MD

Extracranial-intracranial bypass, one; clinical trials, nil

H A F Dudley, FRCs 389

Microdiets

M J Hall, MRCP; J Marks, FRCP 389

Nuclear magnetic resonance imaging

CE Bennett, FRCR, and R D Hoare, FRCP ..... 390
Prevention of recurrent acute cystitis by methenamine hippurate

W Brumfitt, FRCPATH, and J M T Hamilton-

Miller; S Cronberg, $\mathrm{MD}$, and others.

Converting enzyme inhibition and kidney function in normotensive diabetic patients with persistent microalbuminuria PH Winocour, MRCP, and others ...

Loin pain and haematuria syndrome

S M W Hutchison, MRCP; Y T Konttinen, MD, and others.................

AIDS: a faltering step

I Mohammed, FRCPI, and others ................

After safe sex, safe surgery?

K Lafferty, FRCS, and A P Wyatt, FRCS ....... 392

Halothane hepatitis in children

JF Mayhew, MD ............................... 392

The cost of nursing

K W M Scott, FRCPATH........................ 393

References for junior doctors

PG P Lawler, FFARCS ....................... 393
Secrecy and distinction awards

$S$ Bourne, FRCPSYCH, and P Bruggen,

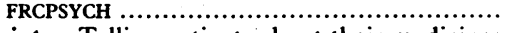

(C W Koenigsberger); Evaluation of portable haemoglobinometer in general practice ( $R$ Quinn); Lymphoedema of the arm (Helen J

Stewart, J D E Knox)............................

Elective surgery in rural east Africa (T G Harland); Exploring therapeutic risks (G Venning); Mortality from myocardial infarction in different types of hospitals (W James and S Dharmavaratha); Resuscitating resuscitation (J F Searle); Diagnosing pulmonary thromboembolism ( $\mathrm{W}$ Watkin and $\mathrm{C} C$ Evans); Measles: who pays the cost? (Allison Streetly); Contamination of dropper bottles with tear fluid in an ophthalmic outpatient clinic (B W Cromie); Preventing alcohol and tobacco abuse (A S Amsden); Alcohol consumption and the risk of alcohol related cirrhosis (K G Green).......................... 394

All letters must be typed with double spacing and signed by all authors.

- No letter should be more than 400 words.

- For letters on scientific subjects we normally reserve our correspondence columns for those relating to issues discussed recently (within six weeks) in the BMF.

- We do not routinely acknowledge letters. Please send a stamped addressed envelope if you would like an acknowledgment.

- Because we receive many more letters than we can publish we may shorten those we do print, particularly when we receive several on the same subject.

\title{
Postoperative thromboembolic disease and oral contraceptives
}

SIR,-The relation between postoperative thromboembolic disease and the combined oral contraceptive pill is now well established. ${ }^{1-5}$ Guidelines have been suggested by Guillebaud ${ }^{1}$ and incorporated into the British National Formulary in order to correct misunderstandings and minimise the risk of unwanted pregnancy. ${ }^{6}$ In addition, the subject has been extensively discussed in medical correspondence. ${ }^{7-9}$

Many anaesthetists, however, have noted with concern that there is still considerable confusion about this matter. Women admitted for major surgery continue to arrive in hospital still using combined oral contraception; conversely, many other women have their minor surgery unnecessarily postponed, often for three months. The anaesthetist is often expected to resolve this problem at a preoperative visit.

Both circumstances are avoidable. It is clearly the responsibility of the surgeon to elicit the relevant history in the outpatient department. When major surgery is planned the patient should be counselled and given at least one month's notice of admission. This should not be impossible in view of the fairly small proportion of admissions accounted for by this population. In the case of minor surgery the patient can be reassured that any increase in risk is minimal in comparison with that of pregnancy. Whatever advice is given should also be included in correspondence to the patient's general practitioner. Junior surgical staff can be instructed on this topic in a matter of minutes, and such tuition would need repeating only every six months.

Why, then, is there still a problem? We believe that the answer is threefold: firstly, lack of knowledge; secondly, failure to organise an efficient scheme for detecting, advising, and admitting these patients; and, thirdly, apprehension engendered by a case reported in the Medical Defence Union's annual report for $1986 .^{10}$ This has been widely misinterpreted as implicating a contraceptive pill in the occurrence of a brainstem thrombosis under anaesthesia. Careful reading of the report, however, shows that no such thrombosis occurred, and when we contacted the Medical Defence Union for further details we were told that the settlement made no reference to the contraceptive pill.

Postoperative thromboembolic disease is primarily a complication of surgery; we suggest that the onus of counselling the patient, or cancelling the operation, should no longer be placed on the anaesthetist. The evening before the list is not the time to discuss such a matter; the patient suffers needless anxiety, and no useful contribution to her management can be made.

Nigel Puttick

Department of Anaesthetics,

University of Wales College of Medicine,

Cardiff CF4 4XW

1 Guillebaud J. Surgery and the pill. BrMed f 1985;291:498-9.

Stadel BV.- Oral contraceptives and cardiovascular disease. N Engl f Med 1981;305:612-8.

Stadel BV. Oral contraceptives and cardiovascular disease. N Engl f Med 1981;305:672-7.

4 Sagar S, Stamatakis JD, Thomas DP, Kakkar VV. Ora contraceptives, antithrombin III activity, and postoperative deep vein

5 Vessey MP, Doll R, Fairbairn AS, et al. Postoperative thrombo- mbolism and the use of oral contraceptives. $\mathrm{Br} \mathrm{Med} \mathcal{F}$ 1970;iii:123-6.

6 Canter RJ, Pryce J. Risk of pregnancy while waiting for an operation. BrMed f 1985;291:516.

Waldram M. Surgery and the pill. Br Med f 1985;291:742.

8 Dyson PHP. Surgery and the pill. BrMed f 1985;291:899. 9 Guillebaud I. Surgery and the pill. Br Med F 1985;291:1201. 10 Medical Defence Union. Annual report. London: Medical Defence Union, 1986: 19.

\section{Pyomyositis associated with hepatitis}

SIR,-Dr R A Watts and colleagues (13 June, p 1524) describe a case of pyomyositis in a patient with antibodies to the human immunodeficiency virus; we recently saw a patient with pyomyositis associated with hepatitis $\mathrm{A}$ infection, which has also not previously been reported.

A 21 year old heterosexual naval engineer was admitted with fever, hepatosplenomegaly, and painful swelling of the right thigh. He had just returned from a four month voyage to the near east, during which six crew members had fallen ill with infectious hepatitis. Five of them made uncomplicated recoveries, but our patient, two weeks after the onset of jaundice, developed bilateral thigh pain and swelling. The left thigh improved spontaneously, but the right thigh became more painful, and four weeks after the onset of symptoms he could not bear weight on the right leg. There was no history of trauma, skin lesions, or intramuscular injections. On examination he was feverish $\left(38.5^{\circ} \mathrm{C}\right)$ and had moderate hepatosplenomegaly and a swollen, woody, and hard right thigh. A test for hepatitis A IgM yielded 
positive results, and white cell count was $14 \cdot 6 \times$ $10^{9} / 1$, with moderate neutrophil leucocytosis. Bilirubin concentration was $33 \mathrm{nmol} / \mathrm{l}$, aspartate transaminase activity $56 \mathrm{U} / \mathrm{l}$, and alkaline phosphatase activity $483 \mathrm{U} / 1$. Ultrasound and computed tomography showed an intramuscular abscess (figure). Sixty millilitres of thick creamy pus was aspirated, from which was cultured cloxacillin sensitive, penicillin resistant Staphylococcus aureus. He was treated for three weeks with cloxacillin. Ultrasound examination was repeated weekly, and by the fifth week there was no sign of a muscular lesion. He made a full recovery.
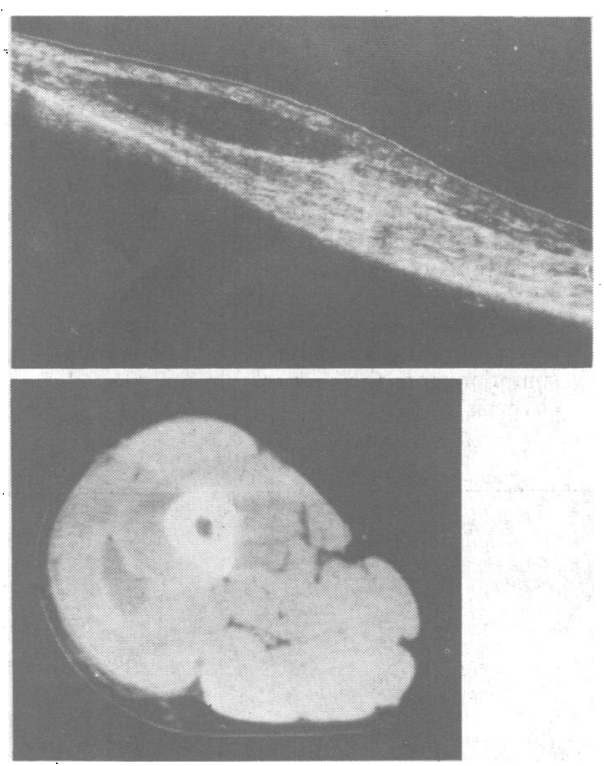

Ultrasonic longitudinal view (top) and computed tomogram (bottom) of patient's right thigh, showing intramuscular abscess.

Pyomyositis is a bacterial infection of skeletal muscle that proceeds to abscess formation. It is endemic among the indigenous population of most tropical countries. ${ }^{1}$ It remains rare in temperate climates, although it is being recognised more often, but not always in association with foreign travel. It has been reported in association with diabetes mellitus, ${ }^{2}$ heroin addiction, ${ }^{3}$ and haematological malignancy. ${ }^{4}$ In tropical countries men are affected twice as commonly as women, and the right hand side of the body is affected more often than the left; evidence supporting viral infection causing muscle damage before bacterial invasion has been scanty. The abscesses traditionally require open surgical drainage; our patient was unusual in responding to conservative measures. Rarely, the infection spreads to the lung, heart, and brain. ${ }^{5}$

We thank Professor J B L Howell for allowing us to report this case.

LINDSAY Dow GINA ALLEN

Southampton General Hospital

Southampton SO9 4XY.

GILES ELRINGTON

Royal Free Hospital

London NW3 20 G

1 Horn CV, Masters S. Pyomyositis tropicans in Uganda. E Ajr Med f 1968;45:463-71.

2 Gibson RK, Rosenthal SJ, Lukert BP. Pyomyositis-increasing recognition in temperate climates. Am $\mathcal{Y}$ Med 1984;77:768-72. 3 Alavi IA, Smith EC, Latoo H. Tropical myositis. N Engl f Med 1971;284:854.

4 Mitsuyasu R, Gale RP. Bacterial pyomyositis in a patient with aplastic anaemia. Postgrad Med F 1980;77:768-72.

5 Shepherd JJ. Tropical myositis-is it an entity and what is its cause? Lancet 1983;ii:1240-2.

\section{Delivery after caesarean section}

SIR,-We have recently completed a 10 year review of lower uterine scar ruptures at our hospital, and we thus found the article by Dr B G Molloy and colleagues (27 June, p 1645) particularly interesting.

We strongly endorse their recommendation that "trial of scar" patients should have electronic fetal monitoring, as all of the babies in our cases of scar rupture that were delivered abdominally showed cardiotocographic abnormalities. We were, however, surprised at the absence of lower abdominal pain or tenderness in all of their cases of scar rupture. Unlike Dr Molloy and coworkers, we classified our cases as complete or incomplete rupture depending on whether the visceral peritoneum was affected. All four of our patients with complete rupture experienced abdominal pain, including the two who received epidural analgesia. In contrast, the only three patients in the incomplete rupture group who received epidural analgesia did not experience abdominal pain, although the other three patients in this group, who did not receive epidural analgesia, did experience pain. This difference leads us to conclude that the pain of complete rupture may break through the epidural blockade, whereas the pain of incomplete rupture does not.

We believe that the lack of standardised classification of uterine scar ruptures, together with a failure to correlate the severity of scar rupture with the presence of abdominal pain, may be the reason for the controversy regarding the use of epidural analgesia in such patients.

P MAOURIS

Department of Obstetrics and Gynaecology, University Hospital of South Manchester, Manchester M20 8LR

P MACROW

SIR,-Dr B G Molloy and colleagues (27 June, p 1645) report that in 1781 patients allowed to go into labour after one previous caesarean section in Dublin between 1979 and 1984 the emergency caesarean section rate was $\mathbf{9 \cdot 2} \%$. In London we studied the outcome in 546 similar patients during 1980-4 and found that the emergency caesarean section rate was $27 \cdot 1 \%$. Labour was induced in $35.7 \%$ of cases $(n=195)$ compared with $23 \cdot 5 \%$ $(n=418)$ in the Dublin series $(p<0.001)$. There was also a higher rate of scar rupture in our series: $1.7 \%(n=9)$ compared with $0.45 \%(n=8)(p<0.01)$.

In 1985 a more selective approach to induction of labour was adopted in patients who had had a previous caesarean section. As a result, in the next 128 such patients the induction rate fell to $22.7 \%(p<0.02)$. These changes in management were also associated with a fall in the repeat caesarean section rate to $21.9 \%(p<0.01)$, and there was only one case of scar rupture, a rate of $0.8 \%$ compared with $1.7 \%(p>0.5)$.

We believe that the better results reported from Dublin are due to differences in obstetric management rather than differences in population. This belief is supported by the improved results in our unit after changes in obstetric management. Furthermore, we have previously shown that the same management of labour may achieve similar caesarean section rates in a London population as in a Dublin population. ${ }^{1}$

The statement made by Dr Molloy and coworkers that "induction of labour does not increase the risk of either a repeat caesarean section or rupture of a uterine scar" must be treated with caution. Between 1980 and 1985, of the 10 patients with scar rupture whom we studied, eight had had labour induced and seven had been given oxytocin infusions. This evidence and the fall in the caesarean section rate associated with the fall in the rate of induction of labour suggests that spontaneous onset of labour is safer in mothers who have had a previous caesarean section.

R P GLEESON M J TURNER H GORDON

Northwick Park Hospital

Middlesex HA1 3UJ

Turner MJ, Fox R, Gordon H. Active management of labour. Lancet 1987;i:753-4.

\section{Randomised comparison of early versus late} induction of labour in post-term pregnancy

SIR,-Dr Kåre Augensen and colleagues (9 May, p 1192) make interesting and controversial judgments about trial ethics. They state that "Seeking informed consent of the mothers would, in all likelihood, have invalidated the trial." It is not clear, however, what they mean by invalidated. Would the seeking of informed consent have resulted in a low enrolment rate? This would not necessarily have biased the trial unless the volunteers to be in the study were systematically different from patients in general. This is certainly something that can be evaluated in the trial and does not necessarily invalidate the trial, merely limiting its generalisability to patients dissimilar to those entered in the trial. Is there some other form of loss of validity that would be caused by seeking informed consent?

"Given the short time available between the decision on eligibility and randomisation, we could not expect mothers fully to understand the trial, much less to make a decision on whether to join.' This statement, if generalised, would have enormous implications for trials in perinatal medicine. Are we to presume that women are incompetent to make decisions when time is short? Surely, this would apply to a wide range of interventions in the intrapartum period and in various antepartum and postpartum emergencies, which future studies might address. It has not been an impediment to many studies in the past to obtain informed consent from patients before entering them into trials. Dyson et al obtained informed consent in a multicentre clinical trial addressing the same question, ${ }^{1}$ and another similar trial is currently in progress in Canada, in which informed consent is also being obtained.

Surely, at this end of the twentieth century we must assume that women are reasoning and competent and have the right to be informed. It would be interesting to know whether the chairman of the ethical board of the Norwegian Medical Association or members of the Haukeland Hospital ethical committee were in any way representative of, or sensitive to, the target population in this study. Were any of them women? Were any of them pregnant or of reproductive age? Were there any non-professional consumer representatives on the ethical committee? It would be interesting to survey a group of women in the same circumstances and with the same eligibility criteria as those included in the study to determine their preferences with regard to participation in such a study and their expectations with respect to being informed and having their consent requested to participate in such a study. Obtaining informed consent has been both feasible and acceptable in the conduct of at least two other similar randomised clinical trials. Are we to assume that these trials are invalid, and, if so, on what basis are they judged to be invalid?

Finally, I believe that medical journals have a special responsibility in publishing articles of this type. I would not suggest that the British Medical 